\title{
La recuperación urbana y residencial del centro de Santiago: Nuevos habitantes, cambios socioespaciales significativos
}

\section{Yasna Contreras Gatica}

Geógrafo. Magister en Desarrollo Urbano. Candidata a Doctor en Arquitectura y Estudios Urbanos, Pontificia Universidad Católica de Chile.

RESUMEN | De forma paralela al proceso de expansión suburbana en las ciudades latinoamericanas y, en especial, en Santiago de Chile, se observa un movimiento residencial y espacial centrípeto, que pone en valor los atributos de localización de sus espacios centrales y que lleva a plantear la tesis del regreso a la ciudad consolidada. Dicho movimiento se inicia en los años noventa, cuando el municipio de Santiago lleva a cabo el Plan de Repoblamiento cuyos objetivos se orientaron a la generación de una oferta de vivienda nueva en zonas de deterioro y en barrios consolidados y bien conectados al resto del sistema metropolitano. A esto último, se sumaron obras de mejoramiento vial y urbano, el arribo de oferta cultural y comercial y, por sobre todo, la llegada de nuevos habitantes urbanos, específicamente jóvenes y adultos profesionales y técnicos que posicionaron y consolidaron al centro como uno de los espacios residenciales más dinámicos.

PALABRAS Clave | Centros urbanos, movilidad, gentrificación.

ABSTRACT | Parallel to the process of suburban expansion in the Latin American cities and especially in Santiago of Chile a centrifugal residential and spatial movement is observed. This movement values the attributes of location of central spaces, thus raising the thesis of the return of the consolidated city. This movement begins in the nineties, when the municipality of Santiago carries out a Repopulation Plan that was oriented to the generation of a supply of new housing in of deteriorated zones and in consolidated and well connected districts. Works of road and urban improvement, the arrival of cultural and commercial supply and the arrival of new urban inhabitants --specifically young and adult professionals and technicians, who positioned and consolidated the downtown area as one of the more dynamic residential spaces-were added.

KEY WORDS | Urban centres, mobility, gentrification.

Recibido el 9 de noviembre de 2009, aprobado el 9 de septiembre de 2010.

Correspondencia: Facultad de Arquitectura, Diseño y Estudios Urbanos y Territoriales de la Pontificia Universidad Católica de Chile (PUC). El Comendador 1916, Providencia, Santiago de Chile. Código Postal: 7530091. Teléfono: (562) 3545649 E-mail: yasnacontreras@gmail.com 


\section{El regreso a la ciudad consolidada. Áreas centrales que cobran nuevos sentidos}

Desde la década de los años noventas algunas ciudades latinoamericanas han experimentado dos formas de crecimiento urbano complementarias: un intenso movimiento residencial hacia la periferia (movilidad centrífuga) versus una densificación de espacios centrales (movilidad centrípeta). Esto último sustenta las tesis del "retorno a la ciudad construida" (Carrión, 2001; Rojas, 2004) o a la ciudad consolidada (Poduje, 2010). De ahí que exista una intensa valoración de los espacios centrales como objetos del capital comercial y como opciones residenciales significativas (Bonvalet y Dureau, 2002; Contreras, 2005 y 2008).

El mayor peso que adquieren las áreas centrales estaría asociado a un contexto de transición demográfica, donde existe una reducción significativa de las tasas generales de urbanización que reduce la presión sobre el crecimiento urbano y redirige la mirada hacia el interior de las áreas urbanas (Carrión y Hanley, 2005). Se pasa de una lógica de urbanización centrífuga a una centrípeta donde la localización y la proximidad se convierten en dos atributos preponderantes. La localización como posición en la escala metropolitana sea centro, pericentro o periferia y, la proximidad referida a las relaciones del individuo con su hábitat, su entorno o contextos residenciales (Authier, 2001) así como también, un "recurso a una mediación técnica que permite liberarse de la distancia geográfica" (Kaufmann, 2000, p. 41) y un constructo social que expresa un modo de vida determinado "el citadino".

Resulta, por tanto, significativo comprender qué hay detrás de este movimiento espacial y residencial centrípeto, que posiciona o reposiciona a áreas centrales como Santiago y en qué medida sus atributos de localización permiten a los individuos liberarse de las distancias sociogeográficas. Es posible que sea un movimiento que responde a la necesidad de las personas de articular proximidad laboral y localización residencial, pero también podría responder a un modo de vida urbano determinado que valora habitar en un barrio y practicarlo. Es probable que la centralidad como proximidad geográfica y social al resto del sistema metropolitano asegure conectividad y cercanía a las redes sociales, laborales y familiares.

En las áreas centrales de algunas ciudades latinoamericanas (Buenos Aires, Bogotá, Ciudad de México y Santiago de Chile) se observa una tendencia creciente a la localización de clases medias profesionales y técnicas que ponen en valor los atributos de la centralidad, ya sea material, simbólica o socioespacial. Sin embargo, este movimiento respondería a estilos urbanos del que variables clásicas como la edad, posición del ciclo de vida y condición social no darían cuenta totalmente (Bonvalet y Dureau, 2002).

Para Carrión (2001), tres serían las causalidades tras el retorno a la ciudad consolidada: cambios demográficos, globalización cultural, económica y social y revolución tecnológica. No obstante, los elementos que explican con mayor claridad la recuperación del centro de Santiago son: en primer lugar, la puesta en marcha de un Plan de Repoblamiento orientado a la captura de demandas residenciales heterogé- 
neas en áreas deterioradas pero con interesantes atributos de localización. Esta acción fue clave, especialmente porque atrajo un mercado inmobiliario que si bien no ha estado exento de críticas respecto a la forma de construir (Contreras, 2005, 2006 y 2008) ha posicionado a la Comuna como el espacio de mayor concentración de proyectos residenciales tipo "departamento" dentro del conjunto metropolitano. En segundo lugar, la aplicación del subsidio de renovación urbana de 200 unidades de fomento (US\$ 8.800) facilitó el acceso a una propiedad en zonas de renovación urbana. En tercer lugar, el gobierno local puso en marcha un sinnúmero de obras viales y urbanas, en muchos casos dispersas territorialmente, pero que en conjunto revirtieron la condición de deterioro y la imagen de inseguridad que pesaba sobre el centro. A estos factores se sumaron los cambios sociodemográficos y culturales significativos de la sociedad chilena. Tales mutaciones responden a estructuras familiares cada vez diferenciadas y con elecciones residenciales complejas. De ahí que el centro de la ciudad e incluso las comunas pericentrales capturan a jóvenes que cohabitan por mucho tiempo en casa de sus padres y que en muchos casos son primeras generaciones universitarias. Las estructuras familiares diversificadas están representadas por mujeres divorciadas con o sin hijos, hombres solos o separados, minorías sexuales, migrantes latinoamericanos, entre otros. La mayoría representa a familias monoparentales para quienes la elección residencial no sólo se funda en la proximidad métrica o espacial que asegura el centro, sino que más bien descansa en las proximidades sociogeográficas asociadas a la cercanía o conectividad laboral y a la proximidad a sus redes sociales y familiares (Contreras, 2011).

De aquí que se arguya que en los procesos de movilidad residencial centrípeta, la "localización" cobre un nuevo sentido socioespacial, principalmente para individuos y grupos sociales que están insertos en una movilidad generalizada (Ascher, 2004; Bourdin, 2007) que amplía sus posibilidades de elección residencial, pero que también las complejiza.

Las transformaciones físicas en la comuna de Santiago descansan sobre nuevas edificaciones en altura que ven además, el reciclaje y la rehabilitación como frenos a la inversión. No obstante, iniciativas particulares y cada vez más crecientes complementan el proceso de densificación y ven la rehabilitación y el reciclaje como formas de acceso a la propiedad central.

Amparando la tesis del regreso a la ciudad central se propone en este artículo establecer qué factores explican la recuperación urbana y social de la comuna de Santiago Centro y cuáles son las mutaciones socioespaciales que derivan de ese proceso. Dentro de los procesos característicos destacan: la penetración de segmentos medios de mayores ingresos y con mayor avidez por el consumo (sucesión de clases medias/profesionalización); elitización urbana de algunos barrios patrimonialeshistóricos; universitarización, asociada a la oferta educacional e inmobiliaria; penetración de inversionistas inmobiliarios que ven en el mercado del rental un negocio; migración-tugurización asociada a la llegada de migrantes latinoamericanos en 
zonas de deterioro, especialmente en los barrios Yungay, algunos sectores de Brasil, Lira, Almagro y el centro histórico.

Lo específico en la comuna de Santiago no es la presencia de fenómenos antagónicos y únicos de "renovación versus tugurización", sino más bien los cambios que dichos procesos conllevan en el espacio urbano y el rol que diferentes grupos sociales le asignan al lugar central como opción residencial. Se parte de la tesis que lo particular de la recuperación del centro de Santiago es la persistencia de múltiples fenómenos de cambio socioespacial que tienen lógicas y formas de representación diferenciadas. Del conjunto de cambios socioespaciales reconocidos el artículo centrará la discusión en la penetración de clases medias profesionales y técnicas y los efectos que introducen en los espacios habitados. Esto último en el marco de la tesis doctoral actualmente en curso.

\section{El enfoque metodológico}

La investigación se estructura en tres apartados. La primera parte está consagrada a una discusión teórica sobre la recuperación y el regreso a la ciudad consolidada y específicamente, a las áreas centrales. En la segunda parte se analiza el caso de la comuna de Santiago o área central de la ciudad, revelando los factores que explican su recuperación urbana, residencial y la posición que ocupa a escala metropolitana. En el apartado final se analizan los principales cambios socioespaciales reconocidos desde mediados de los años noventa, en especial la penetración de habitantes de mayores ingresos y las posibilidades de un proceso de gentrificación.

Para caracterizar los rasgos socioeconómicos de los habitantes que arriban a la comuna de Santiago se analizaron las variaciones de los Grupos Socio-Ocupacionales (GSO) propuestos en la metodología de De Mattos, Riffo, Yáñez y Salas (2005). Dos fueron las categorías de mayor análisis: GSO "Dirigentes" y "Medios" por ser representativos de los cambios socio-ocupacionales de la Comuna. Estos datos derivan del Censo de Población y Vivienda (INE) para los años 1992 y 2002. Los dirigentes corresponden a profesionales de las ciencias físicas, químicas y matemáticas y de la ingeniería, profesionales de las ciencias biológicas, la medicina y la salud, otros profesionales científicos e intelectuales, miembros de los poderes Ejecutivo y Legislativo y personal directivo de la administración pública, directores de empresa (tienen tres o más directores). Los medios responden a Fuerzas Armadas, Carabineros e Investigaciones, profesionales de la enseñanza, técnicos y profesionales de nivel medio de las ciencias físicas y químicas, la ingeniería y afines; de las ciencias biológicas, la medicina y salud; maestros e instructores técnicos; otros técnicos medios; oficinistas y empleados en trato directo con el público y gerentes de pequeñas empresas.

Parte de los procesos socioespaciales y observaciones que se presentan en el documento derivan de la aplicación de entrevistas en profundidad en diferentes barrios de la comuna de Santiago. Esto último como parte de la tesis doctoral actualmente en curso. 


\section{El efecto “infilling” y la recuperación urbana de los espacios centrales}

En los últimos treinta años se han producido cambios significativos en la organización espacial de las metrópolis modernas americanas o europeas (Harvey, 2000, 2007; Ascher, 2004; Soja, 2008). Para el caso latinoamericano y más específicamente, Santiago de Chile, la ciudad ha entrado en una fase urbana marcada, de un lado, por el crecimiento difuso más allá de los límites tradicionales de la ciudad y, del otro, por la recuperación de las áreas centrales y pericentrales como opciones residenciales y comerciales. Estamos asistiendo, por tanto, a un escenario donde las movilidades residenciales centrípetas se complementan con las centrífugas (Bonvalet y Dureau, 2000; Contreras y Figueroa, 2008) y dominan centros urbanos que sufren grandes mutaciones socioespaciales.

En un escenario de crecimiento del ingreso, la ciudad de Santiago experimenta una fuerte evolución tanto en los comportamientos ciudadanos como en las formas de movilidad residencial, entendiendo por ésta la propensión o capacidad de las personas o de un grupo a desplazarse de un lugar de residencia a otro. Se entiende lo residencial no sólo como alojamiento principal o habitual (Segaud et al., 2003, p. 298), sino que también como espacio de vida, es decir, los lugares practicados, frecuentados y recorridos por los sujetos (Lindon, 2002).

Existe en la ciudad de Santiago, por consiguiente, una contracorriente significativa de movimientos de población en pro de zonas centrales y pericentrales que llevan a plantear la tesis del "infilling" o retorno a la ciudad consolidada (Poduje, 2010), cuyas causas están asociadas a un crecimiento periférico que pierde velocidad y a transformaciones demográficas, económicas y culturales que comienzan a producirse con mayor intensidad en los espacios centrales y pericentrales, que acogen un número creciente de edificios y que convierten a los departamentos en modelos de viviendas significativos. Asistimos a una metrópolis transformada donde el centralismo se acentúa y no se pierde (Carrión, 2001 y 2005; Borja, 2005; Jaramillo, 2006).

El caso particular de la comuna de Santiago se caracteriza por concentrar un número significativo de bases financieras, gubernamentales y corporaciones de importantes instituciones nacionales, junto a una oferta inmobiliaria que crece, se diversifica y captura las externalidades positivas de una localización central. La penetración de una oferta comercial creciente, en especial cafés, restaurantes, galerías de artes, centros comerciales, junto con obras de mejoramiento vial (extensión de la línea 5 del Metro, proximidad a autopistas como Costanera Norte y Autopista Central) y la construcción de estacionamientos subterráneos le asignan a la centralidad una posición significativa a escala metropolitana.

Este movimiento centrípeto no es casual, responde a cambios socioculturales y demográficos, entre éstos: reducción del tamaño de los hogares, existencia de familias monoparentales, aumento de la jefatura femenina y una oferta inmobiliaria que cubre las expectativas y las demandas residenciales de sus nuevos habitantes y de inversionistas nacionales y extranjeros que colonizan zonas con fuertes atributos de localización, con ventajas en términos de renta y precio del suelo, accesibilidad, conectividad e infraestructura y equipamiento instalado. 


\section{El centro de Santiago, espacio de jerarquía metropolitana}

Hasta la década de los cuarenta, la comuna de Santiago concentraba un importante volumen de población llegando incluso a un "peak" aproximado de 440.000 habitantes, valor que representaba el 46 por ciento del total de población de la ciudad de Santiago. En la década de los años sesenta la población totalizaba casi $402 \mathrm{mil}$ habitantes, sin embargo, en los años setenta ésta se redujo a la mitad llegando a los 298.877 habitantes (-102 por ciento de variación intercensal).

El terremoto que afectó a la ciudad de Santiago en 1985 agudizó aún más las condiciones de deterioro físico, funcional y social de la Comuna, generando con ello un proceso gradual de pauperización residencial, de despoblamiento y de multiplicación de sitios eriazos que más tarde se traducirían en oportunidades de reconstrucción y densificación (Contreras, 2005). Paralelo al proceso de erradicación periférica llevado a cabo por el Estado en los años ochenta, los terrenos abandonados de la comuna de Santiago comenzaron a ser "retomados en parte por nuevos ocupantes ilegales de algunas viviendas deterioradas que no han sido demolidas o por arriendo de tierra para construcción de mediaguas en los interiores de los terrenos que fueran parcialmente despejados mediante demoliciones posteriores al sismo de marzo de 1985" (Necochea e Icaza, 1990, p. 50).

Uno de los pasos determinantes en la recuperación residencial de la Comuna fue la creación de la Corporación de Desarrollo de Santiago (Cordesan), institución privada sin fines de lucro -dependiente del Gobierno Local-cuyas líneas de acción se orientaron a generar mecanismos de confianza que dieran cuenta de que invertir y vivir en el centro era rentable.

En 1987 y bajo la administración del alcalde Carlos Bombal (1981-1987) se llevó a cabo un encuentro comunal a objeto de debatir y analizar la condición de deterioro y la aplicación de políticas que mejoraran la calidad de vida de sus habitantes. Para entonces, la Cordesan encargó el estudio "Imperativo de la Recuperación Urbana: algunos costos de la expansión” (Ureta et al., 1987), cuyas conclusiones demostraron que los costos sociales y económicos de incorporar un nuevo residente en el centro era 16 veces más rentable que localizarlo en la periferia. Estos antecedentes se convirtieron en la piedra angular para la posterior creación de una línea de subsidio habitacional dirigida a la construcción de viviendas en la zonas definidas de renovación urbana y cuyo monto alcanzaría las 200 unidades de fomento (Ureta et al., 1987; Valenzuela, 2000).

Uno de los motores de la posterior densificación en la Comuna estaría asociado a la modificación del Plan Regulador comunal -vigente desde la era de Karl Brunner (1939)-, cuyos objetivos apuntaban a desregular los agrupamientos y alturas establecidos por el plan Brunner. Era necesario generar incentivos a la inversión inmobiliaria a objeto de hacer rentable la localización de residencias y oficinas en un contexto de escasa actividad inmobiliaria habitacional (Saavedra, 2008). Esta modificación marcaría un hito en la posterior renovación residencial y densificación que experimenta el área central desde inicios de los años noventa. Pondrá en 
tensión las formas de reconstrucción y densificación, especialmente en barrios residenciales históricos y patrimoniales, donde sus antiguos residentes exigen la permanencia y se oponen a cambios que no incluyan su participación.

Desde la década de los años noventa asistimos, por ende, a un renacer y a una revalorización del área central y en especial de algunos de sus barrios, que son reflejo de una dinámica inmobiliaria y de una demanda residencial a partir de la cual emerge una nueva movilidad social, que manifiesta los cambios en la estructura productiva, en el aumento del nivel de ingreso, en las inversiones inmobiliarias, en los cambios en la composición familiar, en la creciente feminización de la fuerza de trabajo y las demandas de quienes optan por la centralidad.

El retorno a la democracia significó la llegada al gobierno local del alcalde Jaime Ravinet (1990-2000), quien imprimió un sello particular a la idea de renovar la Comuna. Uno de sus primeros pasos fue la construcción de un acuerdo comunitario con los actores sociales y grupos de interés, respecto a la visión de desarrollo - deseada y posible- en el horizonte del año 2000. A este proceso de participación de la sociedad civil se le denominó "Primera Convención de Santiago" y de allí se desprendieron los principales lineamientos de acción a los que el municipio se abocó de manera prioritaria (Valenzuela, 2000; Contreras, 2005).

La primera causa modeladora de la nueva forma urbana y del rol de la comuna de Santiago como "opción residencial" fue la aplicación del Plan de Repoblamiento. Después de varios años y signos de deterioro y despoblamiento a mediados de los años noventa se verifica un crecimiento del parque de vivienda tipo "departamento". El Plan se inició en el año 1992 y tuvo como propósito captar y organizar la demanda de vivienda nueva y vincularla con proyectos inmobiliarios de la zona de renovación urbana definida por el municipio en 1987. Sus mecanismos de acción se basaron en tres estrategias: i) La captación de inmobiliarias interesadas en invertir en el área central; ii) La creación de una bolsa de demanda para todos aquellos que estuvieran interesados en residir en ella; y, iii) La creación de un banco de terrenos para la compra de terrenos deteriorados, sitios eriazos, entre otros, susceptibles de desarrollar proyectos inmobiliarios. El Plan resultó de la acción combinada entre una oferta de terrenos como mecanismo de gestión orientado a la compra de sitios obsoletos y abandonados, y una demanda residencial (bolsa de demanda), a objeto de capturar a todos los interesados en comprar viviendas en las zonas de densificación (Aravena, 2003).

Una de las estrategias interesantes para generar una imagen de cambio en el área central fue la aplicación del Subsidio de Renovación Urbana, aprobado en el año 1991 para las viviendas que se construyeran en las denominadas "zonas de renovación urbana” y postuladas dentro del sistema general unificado del subsidio habitacional (Valenzuela, 2000). Con el antecedente de la existencia de esta demanda real registrada y organizada por la Cordesan se consolidó el subsidio de renovación urbana. Originalmente, incentivó a la demanda residencial, pero con el tiempo fue la oferta inmobiliaria quien capturó sus beneficios y quien ajustó sus productos y precios a partir del techo propuesto por el subsidio y en función de las demandas de sus nuevos habitantes. 


\section{Una centralidad urbana y laboral que se consolida y perdura}

Desde 1990 a la fecha el municipio de Santiago ha llevado a cabo interesantes obras de mejoramiento del espacio público, específicamente paseos peatonales como calle Huérfanos o Puente, construcción de estacionamientos subterráneos, obras de recuperación de antiguas construcciones, entre otros proyectos orientados a generar una imagen de cambio y de posición en la escena metropolitana. Esto último no exento de críticas, especialmente por la existencia de normas rígidas que dificultan la recuperación de inmuebles históricos y patrimoniales y la escasa o rígida participación de sus antiguos residentes.

Lentamente, la comuna de Santiago ha ido incrementando el número de permisos de edificación para otros usos como oficinas y comercio. A su vez, está inserta en un centro extendido o longitudinal que parte del centro histórico hasta el barrio El Golf en la comuna de Las Condes, ejerciendo un fuerte poder de atracción de destinos no habitacionales. Un informe realizado el año 2009 por la empresa Global Property Solutions, a pesar de reconocer que Las Condes lidera el ranking de metros cuadrados de oficinas a escala metropolitana, pone en relieve que la comuna de Santiago ocupa el segundo lugar en el mercado de oficinas clase A y A+. Las Condes concentraría el 69,7\%; Santiago Centro un 16,8\%, Providencia un 10,4\% y finalmente, Vitacura con un $3,2 \%$. Esto último avala la tesis de un centro que gana jerarquía metropolitana y que es parte de una centralidad extendida.

Que Santiago Centro no lidere el ranking en metros cuadrados de oficinas y comercio no significa que pierda posición a escala metropolitana. Existen, además, otros elementos que la convierten en un nodo metropolitano significativo. El primero de éstos es el rol que cumple en el mercado laboral urbano. En función del total de población migrante que trabaja según los datos del Censo de Población del 2002, el 21,3\% lo hace a la comuna de Santiago (Escolano y Ortiz, 2006). Complementariamente, Contreras y Figueroa (2008), analizando los resultados de la Encuesta Origen y Destino de Viajes “EOD” (Sectra, 2001) constatan que el principal centro de trabajo metropolitano es la comuna de Santiago, lo que expresa su constante vigencia como distrito central de negocios. Luego le siguen las comunas del eje oriente Providencia y Las Condes. Incluso, los resultados de la última EOD (Sectra, 2006) revelan que las zonas centro (comuna de Santiago) y oriente (Providencia, Nuñoa, Las Condes, Vitacura, Lo Barnechea y La Reina) atraen un 21,1\% (1.004.957) y 19,2\% (914.257) del total de desplazamientos intersectoriales a escala metropolitana.

A su vez, el $61 \%$ de los habitantes de la comuna de Santiago declaró en el Censo del año 2002 vivir y trabajar en la comuna central siendo los casos más representativos los barrios que acogieron un mayor número de edificios en altura desde 1990 a la fecha. En los barrios Centro Histórico, Santa Lucía, Forestal, Almagro, Lira y Brasil más del $22 \%$ de su población trabaja y vive en el mismo barrio. La condición de atracción laboral que ejerce la Comuna para quienes la habitan es tan significativa a escala metropolitana, que se convierte en el quinto territorio después 
de San Bernardo, Maipú, Las Condes y Puente Alto en concentrar un importante volumen de su población dentro de su mercado de trabajo interno (Contreras y Figueroa, 2008).

\section{Un mercado inmobiliario que se consolida en el área central}

Cuando se inicia el Plan de Repoblamiento, una de sus principales metas era convertir a la comuna de Santiago en una opción residencial heterogénea socialmente. Desde el inicio del Plan comenzaron a desarrollarse una serie de convenios con inmobiliarias y cooperativas, orientadas a la construcción de edificios que acogieran a residentes de la Comuna y de otros sectores de la ciudad. En las primeras etapas se ofertaban productos inmobiliarios dirigidos a familias nucleares, no obstante, desde finales de los años noventa la oferta inmobiliaria vio en los hogares monoparentales y, especialmente en estructuras familiares diversificadas (solteros, divorciados, otros) y estudiantes de otras regiones o países, sus principales demandas cautivas. De ahí que el producto de mayor oferta dentro de la Comuna sean departamentos entre 600 y 1.000 unidades de fomento (27.000-45.000 dólares) con tamaños promedios que oscilan entre 18 y $35 \mathrm{~m}^{2}$.

De todos los factores que influyeron en la expansión del mercado inmobiliario en el marco del Plan de Repoblamiento, cuatro han sido los dominantes: 1) el subsidio de renovación urbana, 2) la desregulación normativa (flexibilización de la altura), 3) la disponibilidad de terrenos y 4) el "rent gap" (Smith, 1979) o diferencial de rentas entre la renta actual del suelo y su renta potencial derivada del proceso de verticalización y el fuerte marketing inmobiliario. Estos factores combinados posicionaron a la Comuna y al área central como una de las líderes en la producción de viviendas nuevas tipo departamentos a escala metropolitana.

Como se observa en el Cuadro 1, desde el año 2003 la Comuna lidera el ranking de comunas con mayor producción de viviendas anuales, restando importancia a las comunas periféricas (Maipú, Quilicura y Puente Alto) que históricamente la superaban. Se trata de viviendas tipo departamentos cuya tendencia ha sido al alza. En el período 1995-2010 el 78,4\% corresponde a esta tipología y el 21,6\% a casas.

En el Gráfico 1 se observa con detalle la evolución de la oferta de departamentos en el Área Metropolitana de Santiago y el rol de la comuna de Santiago dentro del período 1995-2010. En los últimos 15 años la distribución de la oferta de departamentos ha tenido un vuelco dentro de la ciudad, mientras el centro en 1995 tenía una participación del 10\% de la oferta con un total de 633 departamentos, su progresivo aumento llegó en 1997 a superar al pericentro con 2.710 departamentos. En el año 2005, la situación se equipara entre los tres anillos con un 34\% del total de oferta. Actualmente el centro concentra el 35\% de la oferta con más de 13.000 unidades vendidas. La mayoría de las unidades son ofertadas a menos de 1.000 unidades de fomento (US\$ 45.000) consolidándose la comuna central como el territorio con el precio mínimo más bajo a escala metropolitana. 
CUADRO 1 | Ranking de permisos de edificación por destino "vivienda". Área Metropolitana de Santiago (A.M.S.) y comuna de Santiago $\mathrm{N}^{\circ}$ de unidades 1980- segundo trimestre 2009

\begin{tabular}{|c|c|c|c|c|}
\hline AÑ̃o & AMS & COMUNA STGO. & \% DEL TOTAL AMS & $\begin{array}{l}\text { RANKING } \\
\text { COMUNA }\end{array}$ \\
\hline 1980 & 13.531 & 887 & $6,6 \%$ & 6 \\
\hline 1981 & 20.649 & 472 & $2,3 \%$ & 8 \\
\hline 1982 & 6.847 & 77 & $1,1 \%$ & 9 \\
\hline 1983 & 6.157 & 12 & $0,2 \%$ & 10 \\
\hline 1984 & 9.324 & 172 & $1,8 \%$ & 9 \\
\hline 1985 & 11.539 & 134 & $1,2 \%$ & 14 \\
\hline 1986 & 12.856 & 211 & $1,6 \%$ & 15 \\
\hline 1987 & 14.583 & 283 & $1,9 \%$ & 10 \\
\hline 1988 & 20.487 & 253 & $1,2 \%$ & 18 \\
\hline 1989 & 21.592 & 362 & $1,7 \%$ & 12 \\
\hline 1990 & 30.835 & 170 & $0,6 \%$ & 8 \\
\hline 1991 & 39.313 & 314 & $0,8 \%$ & 12 \\
\hline 1992 & 45.939 & 779 & $1,7 \%$ & 13 \\
\hline 1993 & 53.566 & 948 & $1,8 \%$ & 12 \\
\hline 1994 & 43.453 & 1.122 & $2,6 \%$ & 10 \\
\hline SUBTOTAL 80-94 & 350.671 & 6.196 & & \\
\hline AÑ̃o & AMS & COMUNA STGO. & \% DEL TOTAL AMS & $\begin{array}{c}\text { RANKING } \\
\text { COMUNA }\end{array}$ \\
\hline 1995 & 56.972 & 4.658 & $8,2 \%$ & 3 \\
\hline 1996 & 52.884 & 2.521 & $4,8 \%$ & 7 \\
\hline 1997 & 54.407 & 5.012 & $9,2 \%$ & 3 \\
\hline 1998 & 36.094 & 3.600 & $10,0 \%$ & 2 \\
\hline 1999 & 39.248 & 1.189 & $3,0 \%$ & 10 \\
\hline 2000 & 26.435 & 2.472 & $9,4 \%$ & 3 \\
\hline 2001 & 35.483 & 3.610 & $10,2 \%$ & 3 \\
\hline 2002 & 31.441 & 3.055 & $9,7 \%$ & 4 \\
\hline 2003 & 39.955 & 4.715 & $11,8 \%$ & 1 \\
\hline 2004 & 46.328 & 8.738 & $18,9 \%$ & 1 \\
\hline 2005 & 53.127 & 10.996 & $20,7 \%$ & 1 \\
\hline 2006 & 58.677 & 14.781 & $25,2 \%$ & 1 \\
\hline 2007 & 66.126 & 11.530 & $17,4 \%$ & 1 \\
\hline 2008 & 58.004 & 17.141 & $29,6 \%$ & 1 \\
\hline 2009 & 24.887 & 4.568 & $18,4 \%$ & 1 \\
\hline SUBTOTAL 95-09 & 680.068 & 98.586 & & \\
\hline
\end{tabular}

Fuente elaboración propia. Datos de la Unidad de Repoblamiento de la Cordesan. 


\section{GRÁfico 1 | Oferta de departamentos en el Área Metropolitana de Santiago según anillos}

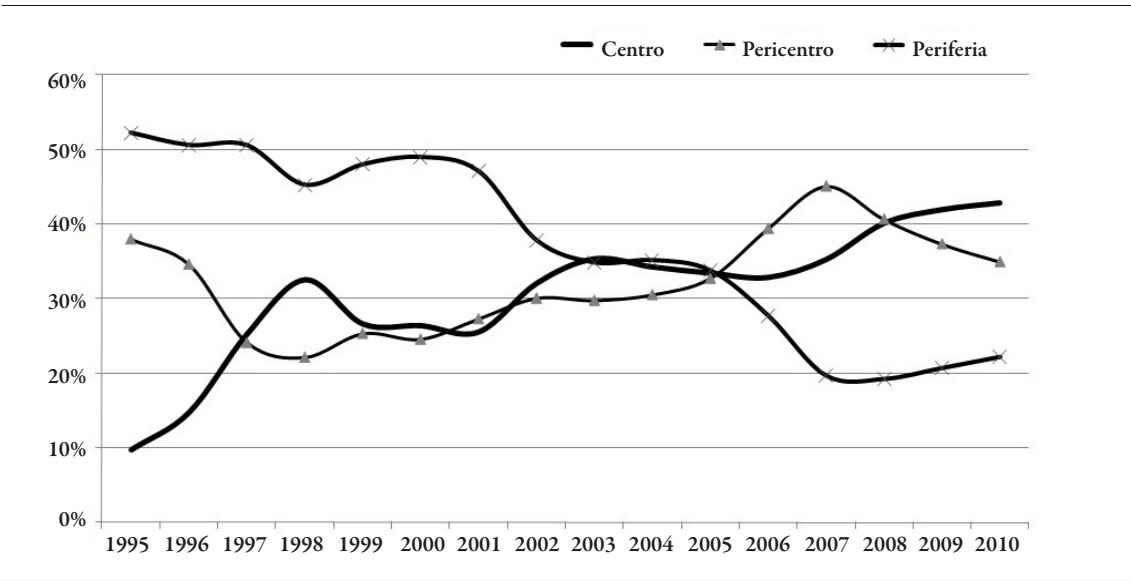

Porcentaje de unidades ofertadas, 1995-2010

fuente Observatorio Habitacional (MinVU) en base a datos Collect.

La posición que adquiere la comuna de Santiago a nivel metropolitano (Cuadro 1) da cuenta de que el mercado inmobiliario encontró en el área central un nicho competitivo que refleja no sólo el acceso de una demanda cautiva a la tipología "departamentos" (Gráfico 1), sino también la alianza que se establece entre constructoras, financieras y el acceso rápido al crédito hipotecario. Lo anterior, amparado además en una normativa urbana flexible a las exigencias y rentabilidades del capital inmobiliario.

Tal como se expone en el Cuadro 2, desde los orígenes del Plan de Repoblamiento se han construido más de 100.000 viviendas nuevas en más de 500 operaciones inmobiliarias y con una media anual de 28 proyectos por año y una tendencia al ascenso, a excepción en los períodos de crisis económicas. De cuatro proyectos construidos en 1990 la oferta pasó a 37 en 1997, e incluso el año 2008 se batió el récord con 65 operaciones y más de 17.000 unidades construidas.

El efecto del tiempo ha revelado que desde 2002 hay una reducción del tamaño del producto ofertado, asociado a un mercado inmobiliario que rentabiliza sus productos y metros cuadrados y a una demanda cautiva, en especial de jóvenes profesionales y de rentistas, que ven al área central como un lugar de "tránsito" (Contreras, 2005 y 2008) y como un sitio ideal para la inversión y especulación inmobiliaria. Las fases de mayor dinámica al interior de la Comuna se producen antes del año 1998. Luego de la crisis del Asia Pacífico, la Comuna experimenta un alza por sobre comunas pericentrales, con disponibilidad de terrenos y con una oferta inmobiliaria creciente y diversificada.

En el comienzo del Plan la acción de las cooperativas y de la Cordesan eran claves en el tipo de producto inmobiliario ofertado y en la demanda residencial 
capturada. En sus orígenes se construyeron departamentos sobre los $100 \mathrm{~m}^{2}$, cuyos compradores mayoritarios fueron residentes de la misma Comuna. Sin embargo, la ampliación del mercado de departamentos hacia otras comunas de la ciudad, la revalorización del metro cuadrado y nuevas demandas residenciales redundaron en productos inmobiliarios de menor tamaño. El producto que se oferta responde a una población "con alta rotación" y con usos acotados en el tiempo, lo que podría ser síntoma de un deterioro posterior. Es aquí donde el rol del gobierno local y de las políticas de desarrollo urbano son claves, en términos de especializar o no al centro de la ciudad como el nicho inmobiliario de los hogares monoparentales y de las estructuras familiares diferenciadas.

CUADro 2 | Comuna de Santiago. Número de proyectos, viviendas y metros cuadrados construidos. 1990-2008

\begin{tabular}{|c|c|c|c|}
\hline AÑ 0 & $\mathbf{N}^{\circ}$ PROYECTOS & $\mathbf{N}^{\circ}$ VIVIENDAS & $\mathbf{M}^{2}$ \\
\hline 1990 & 4 & 170 & 40.422 \\
\hline 1991 & 6 & 314 & 36.560 \\
\hline 1992 & 15 & 779 & 69.543 \\
\hline 1993 & 11 & 948 & 73.686 \\
\hline 1994 & 18 & 1.122 & 95.628 \\
\hline 1995 & 36 & 4.658 & 370.212 \\
\hline 1996 & 25 & 2.487 & 205.025 \\
\hline 1997 & 38 & 5.082 & 413.401 \\
\hline 1998 & 24 & 3.639 & 365.057 \\
\hline 1999 & 11 & 1.189 & 90.311 \\
\hline 2000 & 19 & 2.483 & 195.697 \\
\hline 2001 & 27 & 3.610 & 218.440 \\
\hline 2002 & 21 & 3.055 & 176.090 \\
\hline 2003 & 37 & 4.715 & 261.735 \\
\hline 2004 & 46 & 8.738 & 462.049 \\
\hline 2005 & 55 & 11.956 & 606.289 \\
\hline 2006 & 19 & 15.427 & 871.335 \\
\hline 2007 & 27 & 11.774 & 763.173 \\
\hline 2008 & 65 & 17.000 & 869.430 \\
\hline TOTAL & 504 & 99.146 & 6.184 .083 \\
\hline
\end{tabular}

FUENTE Elaborado a PARTir de Datos de Cordesan ( ${ }^{\circ}$ De PROyeCtos); Municipalidad de Santiago; CámaRa Chilena de la Construcción. 1990-2008. 
Área central de Santiago: ¿Un espacio de múltiples procesos de cambio socioespacial?

Desde inicios del Plan de Repoblamiento hasta la fecha, diferentes barrios de la Comuna han sufrido mutaciones significativas, algunas directamente asociadas a la verticalización y densificación derivada del Plan, y otras relativas a iniciativas particulares que ven en el deterioro una oportunidad de inversión. El poder territorial de universidades y centros de educación superior también es significativo en algunas calles y barrios de la Comuna, específicamente República, Ejército, Brasil, Concha y Toro, Yungay y Lira. Dicho poder se traduce en la recuperación y reciclaje de antiguas casonas convirtiendo amplios espacios de la centralidad en verdaderos barrios universitarios, donde los usos colindantes son complementarios a sus funciones y donde las críticas de sus antiguos residentes van en aumento, principalmente por las deseconomías y dualidades propias a tales usos.

Lo particular del cambio socioespacial en la comuna de Santiago es la persistencia de múltiples fenómenos que tienen lógicas y formas de representación diferenciadas, actores diferentes, espacios y tiempos convergentes. Lo diferente no es la presencia de fenómenos antagónicos (tugurización $\mathrm{v} / \mathrm{s}$ renovación), sino más bien las mutaciones que dichos procesos conllevan en el espacio urbano y el rol que éstos asignan al centro como una opción residencial para habitantes de mayores ingresos y para móviles de menores ingresos (mayoritariamente migrantes latinoamericanos) que valoran la centralidad y que imprimen una condición de mezcla social al centro de la ciudad. A continuación se revisan algunas de esas mutaciones:

\section{Intensa movilidad residencial de Nuevos Habitantes Urbanos: ¿quiénes son, qué es lo nuevo?}

La penetración del capital privado inmobiliario y las acciones conjuntas entre gobierno local y Corporación de Desarrollo para Santiago (Cordesan) han generado una imagen de cambio del centro de la ciudad como opción residencial significativa. El Cuadro 3 da cuenta de los volúmenes relativos y significativos de movilidad residencial centrípeta. Si bien en la Comuna se produjo un éxodo de casi el $50 \%$ de su población ( 109.826 personas) hay un ingreso de casi un $40 \%$ de nuevos residentes (79.641), que más que sustentar la tesis del despoblamiento en el centro es reveladora de una contracorriente muy significativa que expresa movimientos de habitantes hacia lugares centrales (Contreras, 2006 y 2008; Contreras y Figueroa, 2008).

Las transformaciones socioespaciales están asociadas, además, a una reducción del tamaño promedio del hogar el que pasó de 3,5 a 2,8 personas en el período intercensal 1992 y 2002. Existe también un proceso de recambio de hogares extensos hacia otros más pequeños. Hay un aumento de los hogares unipersonales de 9.915 (15,3\%) en 1992 a 20.860 (28,9\%) (Rodríguez, 2007). Este proceso, aunque no es capaz de contrarrestar la tendencia hacia la periferización, es elocuente en distinguir la preferencia de muchos habitantes santiaguinos por la centralidad, como 
un proceso centrípeto complementario al del movimiento centrífugo (Contreras y Figueroa, 2008).

CUADro 3 | Movilidad residencial de los habitantes del Área Metropolitana de Santiago (según anillos)

\begin{tabular}{l|l|l|l|l|l}
\hline \multicolumn{1}{c|}{ ANILLO } & \multicolumn{1}{c|}{$\begin{array}{c}\text { POBLACIÓN } \\
\mathbf{1 9 9 2}\end{array}$} & \multicolumn{1}{c|}{ ENTRADAS } & \multicolumn{1}{c|}{ SALIDAS } & DIFERENCIA & \multicolumn{1}{c}{$\begin{array}{c}\text { POBLACIÓN } \\
\mathbf{2 0 0 2}\end{array}$} \\
\hline (1) Centro & 230.977 & 79.641 & -109.826 & -30.185 & 200.792 \\
(2) Pericentro & 2.301 .695 & 444.037 & -592.998 & -148.961 & 2.152 .734 \\
(3) Periferia compacta & 2.368 .751 & 784.114 & -93.370 & 690.744 & 3.246 .235 \\
(4) Periferia difusa & 350.113 & 71.411 & -39.900 & 31.511 & 461.424 \\
\hline
\end{tabular}

LOS ANILLOS METROPOLITANOS SE CONSIDERAN DE LA SIGUIENTE FORMA:

(1) Centro: Comuna de Santiago

(2) Comunas pericentrales que bordean Santiago Centro: Renca, Independencia, Recoleta, Lo Prado, Quinta Normal, Estación Central, PAC, San Miguel, Macul, San Joaquín, Nuñoa, Providencia

(3) Periferia Compacta: Maipú, Pudahuel, Cerro Navia, Huechuraba, Vitacura, Las Condes, La Reina, Peñalolén, La Florida, Puente Alto, El Bosque, La Cisterna, Lo Espejo, Cerrillos, Maipú, Pudahuel

(4) Periferia Difusa. Lo Barnechea, Lampa, Colina, Pirque, Padre Hurtado y Calera de Tango

fuente Contreras y Figueroa (2008).

\section{¿Quiénes son estos nuevos habitantes?}

Las investigaciones de De Mattos et al. (2005 y 2008) dan cuenta de la importancia que adquieren los profesionales de la enseñanza y los técnicos en la comuna de Santiago. Estos se ubican y concentran mayoritariamente en los barrios Lira-Almagro principalmente en torno al corredor Santa Isabel, República, Ejército, Brasil, Balmaceda, Parque O'Higgins y Club Hípico. Estos barrios atraen un número creciente de ofertas inmobiliarias de departamentos de uno, dos y tres dormitorios, aunque existen algunas zonas del centro histórico tradicional especializadas en departamentos de un dormitorio.

Figueroa (2006) asegura que uno de los fenómenos sociales interesantes en el área central de la ciudad es la penetración de jóvenes que expresan una fuerte apreciación por los centros urbanos. Ellos son representativos de una serie de valores urbanos que se tornan atractivos e interesantes. La oferta cultural, la comodidad de desplazamiento (que significa la renuncia al uso indiscriminado del automóvil) y la preferencia por una "vida metropolitana" han hecho que los habitantes individuales y de las jóvenes parejas aún sin hijos muestren una gran preferencia por las áreas centrales. El impacto de la generación "yuppie" en el centro de Santiago ha producido desde inicios de los noventa un proceso de "pionerización" en palabras de Appleyard (1979) o bien "dinkización" (dinks: doble sueldo sin hijos), es decir, penetración de jóvenes profesionales y estudiantes sin hijos, mujeres solteras, mujeres separadas con hijos, artistas, entre otros (Contreras, 2005 y 2008).

Existe en la Comuna un aumento significativo de personas que han cursado al menos un año de universidad. Tal como lo presentan Scolano y Ortiz (2007) las 
comunas de Santiago, Providencia y Las Condes son los tres territorios metropolitanos que atraen el mayor número de migrantes calificados (profesionales). En conjunto convocan un 57\% del total de los desplazamientos diarios de trabajadores profesionales siendo, además, estas mismas comunas las que poseen la mayor proporción de profesionales que ha migrado hacia ellas.

Quienes llegan a la comuna de Santiago son en un $42 \%$ profesionales que provienen en un $25 \%$ de otras ciudades del país, especialmente Antofagasta, Concepción y Valparaíso. Las razones mayoritarias de la elección y movilidad residencial son el trabajo y el estudio. El resto de los inmigrantes del centro provienen de territorios contiguos, principalmente de comunas pericentrales favorecidos por una oferta inmobiliaria que preferentemente se ha orientado a la demanda de jóvenes profesionales y estudiantes (Contreras, 2005 y 2008).

Revisando las categorías socio-ocupacionales derivadas del estudio de De Mattos et al. (2005) y aplicándolas al caso de la comuna de Santiago se observa que en el último período intercensal la demanda residencial acoge mayoritariamente a grupos socio-ocupacionales medios y medios altos, que tienden a localizarse en los barrios con mayor transformación física, entre éstos Brasil, Yungay, República, Ejército, Centro Histórico, Lira y Almagro.

Tal como se expone en el cuadro 4 el área central presenta un aumento significativo del grupo dirigentes pasando de 7.690 a 13.675 personas, es decir, experimenta una variación porcentual significativa de un 6,0\% en el período intercensal 1992 y 2002. En orden de importancia le siguen los GSO medios cuya variación intercensal fue de 4,3\%. El resto de los GSO se caracteriza por ser poco representativos a escala comunal, no obstante, la reducción de los GSO obreros (-6,7\%) daría cuenta de un proceso creciente de desproletarización.

CUADro 4 | Comuna de Santiago. Cambios en las categorías socio-ocupacionales, 1992 y 2002

\begin{tabular}{l|c|c|c}
\hline Grupo Socioocupacional -GSO & $\mathbf{1 9 9 2}$ & $\mathbf{2 0 0 2}$ & Var. Porcentual 92-02 \\
\hline Dirigentes & 7.690 & 13.675 & $\mathbf{6 , 0 \%}$ \\
\hline Medios & 37.417 & 43.157 & $\mathbf{4 , 3 \%}$ \\
\hline Obreros & 16.440 & 10.888 & $\mathbf{- 6 , 7 \%}$ \\
\hline Trabajadores del Comercio y Servicios & 13.568 & 14.400 & $\mathbf{6 , 1 \%}$ \\
\hline Trabajadores No Calificados & 13.976 & 10.919 & $\mathbf{- 3 , 9 \%}$ \\
\hline Agrícolas & 354 & 448 & $\mathbf{0 , 1 \%}$ \\
\hline Totales & $\mathbf{8 9 . 4 4 5}$ & $\mathbf{9 3 . 4 8 7}$ & \\
\hline
\end{tabular}

fuente elaboración propia. Procesamiento de Censos de Población y Vivienda, INE, 1992 y 2002.

Del total de dirigentes que migran hacia los barrios de la Comuna, la mayoría se concentra en el centro histórico, específicamente en los barrios Forestal, Lastarria y de manera dispersa en el centro histórico tradicional en torno a las calles Cate- 
dral, Morandé y Santo Domingo, ejes concentradores de una oferta inmobiliaria orientada mayoritariamente a hogares monoparentales. Se trata de profesionales de las ciencias y otros intelectuales, aunque existe también un número menor de pequeños empresarios que desarrollan negocios dentro de la misma Comuna o en territorios bordes.

Respecto de los GSO medios, éstos sufrieron una variación porcentual de 4,3\% pasando de 37.417 a 43.157 personas. El mayor aporte dentro de este grupo proviene de otros técnicos cuya variación porcentual 1992-2002 fue de 484\%, significando con ello la incorporación de más de 13.000 personas. En orden de importancia le siguen los profesionales de la enseñanza con una variación de 226\%, es decir, más de 3.000 personas se agregan a estas subcategorías (Cuadro 4).

Finalmente, los grupos medios son significativos en toda la Comuna, comprobándose que la mayoría de sus barrios concentran más de un $20 \%$ de dicha categoría. Se observa una fuerte expansión del número de barrios con presencia relativa de este grupo. En 1992 los casos significativos eran los barrios Centro Histórico (22,9\%), San Francisco (21,9\%), Brasil (20\%) y Lira (19,9\%). En el 2002 se amplía el grupo de territorios con más del $20 \%$ de su población dentro de este grupo, siendo los casos más representativos los barrios Parque Club Hípico (30\%), Sta. Lucía Forestal (29\%), Centro Histórico (28\%), Concha y Toro (27\%), Brasil y Lira (26\%) y Ejército (25\%). Muchos de los grupos medios corresponden a primeras generaciones universitarias que provienen mayoritariamente de comunas bordes o periféricas y que ven en el acceso a un departamento central el inicio de su carrera residencial. Dentro de estos grupos también encontramos inversionistas inmobiliarios, especialmente profesionales jóvenes egresados que cohabitan en casa de sus padres (Las Condes, Providencia, Nuñoa o Vitacura) y que ven en la compra de un departamento un mecanismo de inversión futura. A este grupo se suman padres de estudiantes universitarios que provienen de otras ciudades del país y que acceden a una propiedad central que les reporta mayores beneficios económicos y mayores rentabilidades frente a la opción de arrendar. Se suman, finalmente, inversionistas privados que compran pisos completos orientando su oferta a las clases medias profesionales y técnicas que quieren arrendar y habitar en la centralidad.

\section{¿Qué es lo nuevo de estos habitantes?}

En función de las entrevistas realizadas en diferentes barrios de la comuna de Santiago se entregan algunas conclusiones iniciales derivadas de su análisis. De manera general, se asume que lo nuevo de los individuos que arriban a la comuna de Santiago se asocia a lo menos a las siguientes causalidades. En primer lugar, la centralidad constituye su primera elección residencial después de abandonar la vivienda de sus padres (decohabitación). En segundo lugar, muchos de éstos acceden a la propiedad de un inmueble en la centralidad como elección residencial futura, como inicio del recorrido residencial o como mecanismo de inversión ("mercado del rental"). En algunos casos estaríamos en presencia de habitantes con un recorrido residencial regresivo (Lévy, 2001) luego de una pérdida de empleo o de un divorcio. Para muchos la centralidad tendrá un sentido objetivo y material (recorrido residencial promo- 
cional) como nodo a partir del cual se asegura la intermodalidad y la conectividad al resto del sistema metropolitano.

En tercer lugar, buscan establecer diferencias sociales a partir del barrio que escogen, los lugares que frecuentan, sus pautas de consumos, la relación entre sí y con los otros. Finalmente, lo nuevo de estos móviles urbanos es que sus formas y prácticas de movilidad no sólo están replegadas al espacio inmediato, es decir, al departamento o el barrio como ataño, sino más bien sus movilidades y prácticas cotidianas transitan por las múltiples escalas territoriales (centro, pericentro, periferia e incluso otra ciudad del país) y esferas que conforman su vida cotidiana. El tránsito por múltiples escalas territoriales también se explica por los lazos que estos habitantes tienen con sus espacios de origen y con sus redes sociales y familiares. Esto último lleva a plantear la tesis de habitantes con anclajes metropolitanos superpuestos a los locales.

Se trata de habitantes con ingresos similares o superiores a la población preexistente, no obstante, su arribo no ha significado desplazamientos de habitantes de menores ingresos salvo contadas excepciones: algunas manzanas de los barrios Brasil, Yungay (Contreras, 2005) y en torno a la avenida Santa Isabel en los barrios Lira-Almagro. La mayoría de estos habitantes accede a una vivienda nueva en edificios sobre diez pisos, es propietario y se vio favorecido por acceso a créditos hipotecarios diversos, con tasas de interés bajas y en menores casos, respaldados por el subsidio de renovación urbana. Son menores los casos de nuevos habitantes que rehabilitan o reciclan antiguas construcciones. Esto último es específico a los barrios Forestal, Lastarria, algunas calles del barrio Yungay, Brasil y República. Se trata también de clases medias con movilidad social ascendente pero también de élites locales que ven a estos diferentes barrios como elecciones residenciales significativas y permanentes.

\section{¿Nuevos habitantes, reflejo de un proceso de gentrificación?}

Algunas investigaciones (Contreras, 2003, 2005 y 2008); (Hidalgo et al., 2003); De Mattos et al. (2005 y 2007) refieren a un proceso de elitización o gentrificación de algunos barrios de la comuna de Santiago. Se asume, de aquí en adelante, que la "gentrificación" es un proceso de recomposición social del espacio urbano caracterizado por la llegada de habitantes de mayores ingresos en zonas deterioradas, y por el posterior desplazamiento de habitantes de menores ingresos. En su acepción original (Glass, 1964) la gentrificación se asoció a la penetración de clases medias altas e incluso altas (nobleza), sin embargo, las investigaciones pos Glass y más específicamente la literatura de los años ochenta y noventa (Ley, 1980, 1986; Smith, 1982, 1984; Hamnett, 1991, 2003; Butler, 2007; Lees, Bluter y Wily, 2008; Herzer, 2008 , entre otros) lo observan como un intenso cambio social en el que clases medias reemplazan a población de menores ingresos.

Para el área central de Santiago, Contreras (2005) reconoció una silenciosa y reciente gentrificación que tiene como principal escenario algunos sectores del barrio Yungay y Brasil, mediante estrategias de reciclaje de antiguas casonas deterioradas (calles Lucrecia Valdés, Maipú, Esperanza, Compañía, Maturana, entre otras), o 
a través de la construcción de nuevos edificios tipos "lofts". Se trata de un proceso que ha significado la llegada de población de ingresos superiores respecto de la población preexistente. Sus elecciones residenciales están asociadas a la búsqueda de una vida más prourbana, con mayor mezcla social, con proximidad a redes sociales, familiares y laborales viendo en el reciclaje de antiguas construcciones o en la compra de un departamento tipo loft una forma y estilo de habitar. La penetración del capital comercial en ambos barrios (cafés, restaurantes, galerías de artes, librerías, entre otros) ha reforzado y valorizado el carácter patrimonial que los caracteriza y las pautas de consumo de estos nuevos habitantes. Sin embargo, el barrio Yungay se constituye actualmente como un espacio que acoge a un número creciente y diversificado de migrantes latinoamericanos, entre éstos, peruanos, ecuatorianos, dominicanos y colombianos que ven en las viviendas deterioradas y en algunos casos abandonas formas de acceso económico a una vivienda central.

En Santiago Centro y en especial en los barrios Brasil y Yungay, existen condiciones de bases para un proceso de gentrificación, especialmente diferencial de rentas y penetración de habitantes de mayores ingresos esencialmente en antiguas viviendas deterioradas y recicladas como edificios lofts. No obstante, la rehabilitación y la recuperación urbana no ha significado la expulsión de antiguos residentes, salvo algunas excepciones. Al parecer estaríamos asistiendo a una gentrificación subjetiva sustentada en algunas investigaciones muy genéricas, que ven al centro de Santiago como un espacio gentrificado a la usanza americana o europea.

En esta misma línea, Rubio (2008) haciendo un estudio de las transformaciones en los barrios Bellas Artes y Lastarria, concluye que dichos barrios en su conjunto "no viven un proceso clásico de gentrificación, ya que no cumplen con dos aspectos básicos del concepto como son: aumento del precio de las viviendas y la elevación del nivel socioeconómico de sus redientes, pero que este fenómeno sí se puede reconocer (al menos incipientemente) en ciertas áreas muy específicas del sector por lo que podríamos identificar una gentrificación puntual de ciertas zonas" (p. 117).

Lo masivo en la comuna de Santiago ha sido un proceso de verticalización-densificación sobre sitios baldíos y el arribo de clases medias profesionales y técnicas que provienen de diferentes comunas de la ciudad de Santiago y la recuperación del comercio popular en zonas de elevada accesibilidad y conectividad. El otro proceso que va en aumento es la tugurización de ciertas manzanas de la Comuna, asociadas a la llegada de migrantes latinoamericanos y de migrantes internos de menores ingresos. Lo menos masivo es la llegada de élites locales, salvo algunas manzanas del barrio Forestal y Lastarria donde tienden a localizarse.

Los datos del último período intercensal son elocuentes en revelar que quienes llegan a la comuna de Santiago son mayoritariamente habitantes de comunas contiguas a éstas, de otras ciudades del país y en menor medida de espacios periféricos. Por tanto, estaríamos en presencia de personas de ingresos similares o levemente superior a la población de origen pero con pautas de consumo más sofisticadas y en aumento.

La aplicación de entrevistas en profundidad en diferentes barrios de la Comuna, en especial en los barrios con mayor densificación (Brasil, Yungay, Lira, Almagro) da cuenta de que en su mayoría quienes llegan tienen una movilidad social 
"ascendente" y ven las áreas centrales como un lugar de paso o de tránsito, fuertemente asociado al ciclo de vida de la mayoría de estos nuevos habitantes (Contreras, 2005). Se trata de un colectivo de profesionales o de jóvenes profesionales que están estudiando o trabajando en la Comuna o muy próxima a ésta.

De manera más oculta y paralela al Plan de Repoblamiento se produjo una primera etapa de un proceso de gentrificación a fines de los ochenta hasta la primera mitad de los años noventa, específicamente en algunas manzanas de los barrios Brasil y Yungay. Dichos cambios obedecieron a iniciativas de particulares y de inmobiliarias con capitales foráneos, como Espacios 2000 Ltda. Se trató de iniciativas privadas orientadas a la restauración y al reciclaje de antiguas casonas deterioradas anteriormente arrendadas o subarrendadas. El proceso acogió mayoritariamente edificios lofts (Figura 1) adaptándolos a los usos y a las nuevas formas de habitar. El mejor ejemplo de una primera oleada de gentrificación ocurrió en los pasajes Adriana Cousiño, Lucrecia Valdés, Hurtado Rodríguez y en las intersecciones de las calles Maipú y Compañía y Huérfanos con Esperanza. Es aquí donde hubo intentos de gentrificación, siendo las demandas mayoritariamente de jóvenes profesionales o adultos profesionales entre 30 a 35 años, médicos, abogados, ingenieros y artistas, quienes valoraban la centralidad y quienes además provenían en un noventa por ciento del cono de altos ingresos de la ciudad (Contreras, 2005 y 2008) y en menor medida del extranjero.

FIGURA 1 | Zonas de verticalización y gentrificación en la comuna de Santiago (barrios Brasil y Yungay)

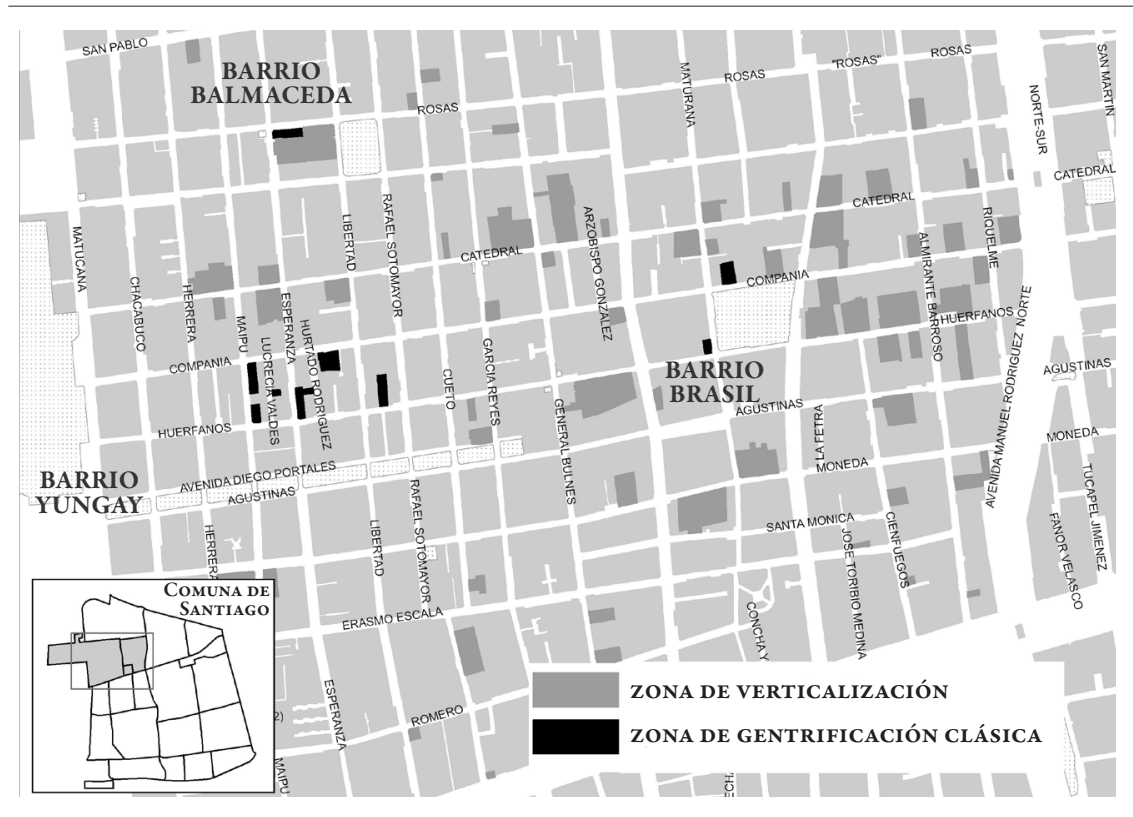

FUENTE ELABORACIÓN PROPIA. 
Existe la creencia de que barrios como Forestal o Lastarria sufren procesos de gentrificación, sin embargo, son áreas que históricamente han acogido a segmentos de altos ingresos, en especial artistas e intelectuales, quienes en un proceso de invasión y sucesión constante siempre han colonizado y ocupado dichos barrios, entregando la posta a sus iguales. Más aún en barrios como Lastarria, a pesar de la penetración masiva de un capital comercial y cultural desde mediados de los años noventa, presenta construcciones en deterioro que acogen mayoritariamente a jóvenes estudiantes con ingresos menores a la población que históricamente lo colonizó. Si bien no se intenta despreciar la tesis del surgimiento de una cultura del consumo como un factor relevante de los cambios que sufren algunos barrios del centro como Forestal y Lastarria, debemos subrayar que esta zona no es objeto de gentrificación ni elitización, sino más bien de una "boutiquización" (Ludeña, 2009; Carrión, 2009) o "musealización” (Ludeña, 2009) de sus espacios públicos y ofertas comerciales.

No es posible replicar un fenómeno tan especial como la gentrificación a toda la comuna de Santiago simplemente porque exista un aumento de grupos socioocupacionales dirigentes e incluso porque exista un aumento macro del estrato socioeconómico ABC1 de 3,8 (1992) a 11,1 (2002) (Contreras, 2008).

La gentrificación es un proceso cíclico y los barrios Yungay y Brasil fueron los primeros en acoger a una demanda residencial que usó el reciclaje y la rehabilitación de antiguas casonas como medio físico para acceder a la vivienda en un espacio central (Figura 1). Es en dichas áreas donde se produjo un desplazamiento de antiguos residentes, en su mayoría arrendatarios de menores ingresos, quienes ocupaban casonas con fuerte deterioro estructural. Es aquí, además, donde llegó población de mayores ingresos respecto a la población original, y es aquí donde hasta finales de los noventa penetró un segmento que valoraba la tradición de los barrios y la arquitectura de sus edificios (Contreras, 2005). Fue aquí donde asociada a la demanda residencial de artistas y profesionales penetró el capital comercial como primera manifestación de un proceso de gentrificación. Hasta el año 2005 era característico ver alguno cafés y restaurantes. Los más clásicos eran el Boulevard Lavaud, La Quinta Esquina, Manos Morenas, entre otros.

En el barrio Brasil y más específicamente en torno a la Plaza Brasil, dos construcciones podrían estar insertas dentro del concepto gentrificación, en especial los edificios lofts Plaza Brasil (1995) y la Comunidad Lofts Plaza Yungay (1997) de la inmobiliaria Centro Verde (Figura 1). Quienes llegaron a vivir mayoritariamente eran jóvenes profesionales, en especial varones, solteros o en pareja, cuyas edades fluctuaban entre los 30 y los 35 años. Sus comunas de orígenes eran el cono de altos ingresos, en especial Vitacura, Las Condes y en menor medida Providencia y Nuñoa. Otros provenían de otras ciudades del país y en menores casos de otras ciudades del mundo. Tal como ocurrió en el barrio Yungay, aquí también penetró un capital comercial, siendo los casos representativos Santo Barrio, El Café, La Canela y los pubs My House, B'Aires, entre otros (Contreras, 2005).

Lo más interesante de los barrios Brasil y Yungay es que desde hace cuatro años las zonas que presentaron signos de una primera etapa de gentrificación se han su- 
mido entre múltiples procesos. En algunos casos, el deterioro vuelve a ser plausible en sectores renovados; la tugurización tiende a convivir con espacios renovados, especialmente las viviendas deterioradas y hacinadas.

Las estrategias de reciclaje y de rehabilitación no fueron parte de un proyecto urbano local y tampoco estuvieron insertas en el Plan de Repoblamiento. Estas respondieron a iniciativas de particulares, quienes valoraban la vida urbana y quienes, además, querían construir una utopía de vuelta a la vida barrial. Inmobiliarias como Espacios 2000 Ltda. quedaron sumidas en el baúl del olvido, carentes de incentivos locales y afectados, además, por un proceso de recambio de habitantes cuyas modalidades masivas son el alquiler. Aún más, el mercado inmobiliario que dominó el área central vio en el mejoramiento físico, en especial, la rehabilitación y el reciclaje como "frenos a la inversión". Era más rentable construir sobre nada y rentabilizar el terreno adquirido (Contreras, 2005). Esa era la lógica capitalista que dominaba al Plan de Repoblamiento.

Si bien es cierto que existió un diferencial de rentas entre la renta actual y la potencial de algunos terrenos, este diferencial simplemente favoreció al capital inmobiliario privado, el que rentabilizó sin importar los ambientes residenciales que dominaron y que dominan muchos barrios en intervención. Estamos, además, en presencia de un centro urbano que ha favorecido la densidad con una política urbana "a corto plazo".

Lo significativo del proceso de cambio socioespacial en la comuna de Santiago, es que en una manzana o calle se puede observar tugurización y deterioro, mientras que metros más allá la renovación urbana, la verticalización, el reciclaje y la llegada de nuevas y sofisticadas ofertas comerciales son los procesos que dominan. De ahí que Santiago Centro sea un mosaico socioespacial interesante de observar.

\section{Conclusiones}

Convertir a la comuna de Santiago en una opción residencial significó la llegada de nuevos habitantes que provenían de diferentes sectores de la ciudad, en especial de comunas pericentrales bordes, periféricas y de otras ciudades del país y con ingresos similares o superiores a la población preexistente. Mayoritariamente, se trata de jóvenes y adultos profesionales, muchos de ellos primeras generaciones universitarias para quienes el centro de Santiago adquiere principalmente un sentido material más que simbólico. Material, porque dada la vulnerabilidad y flexibilidad laboral a la que mucho de éstos se ven sometidos, el centro les asegura conectividad, intermodalidad y proximidad a sus redes sociales y familiares.

Lo interesante de la recuperación del centro de Santiago es que está cargada de un intenso movimiento residencial. No está marcada por el retorno o regreso de élites suburbanas, más bien el arribo de clases medias con movilidad social en "ascenso" que, a su vez, representan a nuevas estructuras familiares diversificadas, específicamente mujeres solas, separadas, viudas profesionales y técnicos, pero también hombres solos, solteros y en menores casos separados. Esto último avalado en las entrevistas realizadas dentro del centro de Santiago. 
Por tanto, estamos en presencia de un centro y de barrios centrales que se especializan en una o más secuencias del curso o recorrido residencial. Se reconocen personas como recorridos residenciales regresivos (Lévy, 2001) entre éstos, mujeres $\mathrm{u}$ hombres divorciados, jóvenes y adultos estudiantes o profesionales que viven un tiempo en la centralidad como propietarios y luego regresan a casa de sus padres o habitan con amigos como arrendatarios, frente a escenarios de vulnerabilidad económica y laboral.

Lo dominante en la comuna de Santiago es un proceso de "verticalización”, donde hay una invasión y sucesión constante de grupos socioeconómicos de ingresos medios similares, con movilidad social "ascendente" y con una valorización heterogénea que va más allá de la simple articulación entre localización del trabajo y residencia.

Se trata además, de una verticalización donde lo positivo es la posibilidad que tienen segmentos de ingresos medios de acceder a una vivienda propia dentro del centro. Lo negativo, es que asociado a la mala calidad de la construcción y a la falta de un proyecto de ciudad, muchos de estos ven al área central como un lugar de tránsito o como el espacio para la inversión y especulación inmobiliaria.

La gentrificación en la comuna de Santiago es de escala puntual y es muy cíclica. En un momento algunas calles del barrio Yungay fueron objeto de este proceso, y hoy la tugurización y el deterioro son los procesos dominantes. Por tanto, está pendiente de parte del Gobierno Local y del Estado repensar una estrategia de renovación residencial duradera, que vea en la gentrificación y en la mezcla social una forma de reconstrucción y de acceso a la propiedad de la vivienda central o pericentral.

También quedaría pendiente revisar si el subsidio de renovación urbana o el subsidio de rehabilitación patrimonial son mecanismos de apoyo suficientes al acceso a la vivienda. Es necesario adecuarlos o modificarlos a las exigencias que imponen hoy el mercado de la vivienda central y la demanda residencial que opta por la centralidad y que incentiva la tesis del regreso a la ciudad construida (Carrión, 2001).

El mayor aprendizaje al escribir este artículo es que son otros los procesos que deberían preocupar el debate sobre los cambios socioespaciales del área central, en especial el susurrado y a veces oculto proceso de especulación inmobiliaria individual y colectiva, que ve en el mercado de departamentos un potencial de rentabilizar la inversión particular. Este es uno de los procesos que pone en riesgo la sustentabilidad de barrios en constante renovación.

Santiago Centro, desde los años noventa ha estado dominado por la utopía del gobierno local y del capital inmobiliario en el afán de repoblar un área que muta en términos sociales, y donde confluyen diferentes demandas residenciales. Una utopía de creer que el fachadismo de antiguas construcciones o el mejoramiento de plazas barriales serían signos de un proyecto urbano claro.

Pese a las críticas respecto a la altura de las construcciones y a la destrucción de algunas zonas residenciales patrimoniales, es dable rescatar que Santiago Centro constituye una opción residencial significativa y creciente. Se convierte en un mosaico social interesante de analizar, por cuanto convergen en él habitantes de ingresos medios, en menor medida de ingresos altos, pero también móviles de bajos ingresos 
que se invisibilizan como actores sociales relevantes del cambio. Es aquí donde las políticas urbanas y habitacionales son determinantes, especialmente para asegurar mezclas sociorresidenciales y estrategias de ocupación equitativa de la centralidad.

La movilidad centrípeta y las elecciones en sectores como la comuna de Santiago revelan procesos intensos de diferenciación social. En una manzana conviven nuevos residentes de ingresos medios, antiguos residentes y migrantes latinoamericanos de bajos ingresos. Cada uno de estos actores imprimen cambios socioespaciales significativos a los barrios que colonizan, pero también reflejan elecciones residenciales diversas y complejas en escenarios de renovación y recuperación urbana.

La recuperación urbana del centro sin lugar a dudas ha sido significativa, especialmente porque clases medias profesionales y técnicas pueden acceder a la vivienda en propiedad en una de las zonas de la ciudad con mayor fertilidad territorial y con mejores atributos de localización. Ello no excluye los elementos negativos del proceso. El repoblamiento no necesariamente ofrece renovación urbana. Más bien una especie de acción inmobiliaria intensiva que analogado a la agricultura puede producir una baja en su productividad. IEURE

\section{Referencias bibliográficas}

Appleyard, D. (1979). The conservation of European Cities. The Massachusetts Institute of Technology, Cambridge, MA: MIT Press.

Aravena, B. (2003). Plan de Repoblamiento. Entrevista realizada el 10 de septiembre. Santiago, Chile.

Ascher, F. (2004). Los nuevos principios del urbanismo: El fin de las ciudades no está al orden del día. España: Alianza editorial.

Authier, J. Y. \& Bidou, C. (2008). La question de la gentrification urbaine. Espaces et sociétés, Vol. 132, No. 1-2, pp. 2-13.

Authier, J. Y. (2001). Du domicile a la ville. Vivre en quartier ancien. París, Francia: Anthropos.

Bonvalet, C. \& Dureau, F. (2000). Los modos de habitar: unas decisiones condicionadas. En Dureau, F. (Ed.). Metrópolos en movimiento: Una comparación internacional. Bogotá: IRD Editions y Economica.

Butler, T. (2007). For gentrification? Environment and Planning A, Vol. 39, pp. 162-181.

Bourdin, A. (Ed.) (2007). Mobilité et écologie urbaine. Paris: Descartes \& Cie.

Carrión, F. (Ed.) (2001). Centros históricos de América Latina y el Caribe. Quito: UNESCO-BID-Ministerio de Cultura y Comunicación de Francia - FLACSO.

Carrión, F. \& Hanley L. (Ed.) (2005). Regeneración y revitalización urbana en las Américas: hacia un Estado estable. Ecuador: Flacso-Wwics-USAID.

Carrión, F. (2009). El centro histórico de Quito. ¿Patrimonio de la humanidad o del mercado? Ponencia presentada en la Facultad de Arquitectura, Diseño y Estudios Urbanos. Pontificia Universidad Católica de Chile. Santiago, Chile.

Contreras, Y. (2005). Dinámica inmobiliaria en el Programa de Repoblamiento: Un análisis a los efectos urbanos y sociales en la comuna de Santiago. Casos de estudio: barrios Brasily Yungay. Tesis Magister en Desarrollo Urbano. Instituto de Estudios Urbanos y Territoriales de la Pontificia Universidad Católica de Chile. Santiago, Chile. 
Contreras, Y. (2008). La gestión inmobiliaria en el centro de Santiago de Chile: ¿El traje a la medida del mercado inmobiliario? Ponencia presentada en X Seminario Rideal, Juárez, México.

Contreras, Y. \& Figueroa, O. (2008). Los patrones de movilidad residencial y cotidiana en la ciudad de Santiago. Ponencia presentada en el X Seminario RII Red Iberoamericana de investigadores sobre globalización y territorio, Querétaro, México.

De Mattos, C.; Riffo, L.; Yáñez, G. \& Salas, X. (2005). Reestructuración del mercado metropolitano de trabajo y cambios socio-territoriales en el Gran Santiago. Santiago: Informe de investigación proyecto Fondecyt 1040838.

Dureau, F. (2002). Bogotá: una doble dinámica de expansión espacial y de densificación de espacios ya urbanizados. En F. Dureau (Ed.). Metrópolis en movimiento: Una comparación internacional. Bogotá: IRD Editions y Economica.

Escolano, S. \& Ortiz, J. (2006). Patrones espaciales de movilidad de la población: algunos efectos en la sociogeografía del Gran Santiago. En C. De Mattos \& R. Hidalgo (Eds.) Santiago de Chile: Movilidad espacial y reconfiguración metropolitana. Santiago: Colección EURE Libros/ Serie Geolibros N8.

Glass R. (1964). London: Aspects of change report 3. London: Centre for Urban Studies, MacGibbon andKee.

Global Property Solutions (2009). Informe del Mercado de oficinas. Tercer trimestre. Recuperado el 10 de marzo de 2010, de http//www.gpsproperty.cl/.../GPS-Informe-Mercado-Oficinas3-Trimestre-2009-Modo-de-compatibilidad.pdf

Hamnett C. (1991). The blind men and the elephant: the explanation of gentrification. Transactions of the Institute of British Geographers. New Series, Vol. 16, No. 2, pp. 173-189.

Hamnett, C. (2003). Gentrification and the Middle-Class remaking of Inner London, 1961-2001. Urban Studies, Vol. 40, No. 12, pp. 2401-2426.

Herzer, H. (2008). Con el corazón mirando al sur. Transformaciones en el sur de la ciudad de Buenos Aires. Buenos Aires: Editorial Espacio.

Instituto Nacional de Estadísticas (INE). Censos de Población y Vivienda, 1970, 1982, 1992 y 2002. Santiago: INE.

Kaufmann, V. (2000). Mobilité quotidienne et dynamiques urbaines. Lausanne: Presses polytechniques et universitaires romandes.

Jaramillo, S. (2006). Reflexiones sobre las políticas de recuperación del centro (y del centro bistórico) de Bogotá. Documento Centro de Estudios sobre Desarrollo Económico - CEDE, Facultad de Economía, Universidad de los Andes. Bogotá, Colombia.

Lees, L.; Slater T. \& Wyly E. (2008). Gentrification. (1a.ed.). New York and London: Routledge Taylor \& Francis Group L.C.

Lefeuvre, M.P. (2005). Introduction: Proximité spatiale et relations sociales. En A. Bourdin, M. Lefeuvre, A. Germain (Eds.). La proximité. Construction politique et experience sociale. Paris: L'Harmattan.

Ley, D. (1980). Liberal ideology and the postindustrial city. Annals of The Association of American Geographers, Vol. 70, No. 2, pp. 238-258.

Ley, D. (1986). Alternative explanations for inner-city gentrification: a Canadian assessment. Annals of The Association of American Geographers, Vol. 76, No. 4, pp. 521-535.

Lévy, J.P. (2001). Parcous d’habitants. En Authier (Ed.). Du domicile á la ville. Paris: Económica. 
Lindón, A. (2002). Trabajo, espacios de vida y cotidianidad. La periferia oriental de la ciudad de México. Scripta Nova Revista Electrónica de Geografía y Ciencias Sociales, Vol. VI, No. 119. Universidad de Barcelona.

Ludeña, W. (2008). Lima-Centro bistórico hoy: transformaciones recientes. Intervenciones y tendencias (20002008). Ponencia presentada en Seminario Lima, Santiago de Chile. Pontificia Universidad Católica de Chile y Pontificia Universidad Católica del Perú, Departamento de Arquitectura. Santiago, Chile.

Necochea, A. \& Icaza, A. (1990). Una estrategia democrática de renovación urbana residencial. El caso de la comuna de Santiago. Eure, Vol. XVI, No. 48, pp. 37-65.

Poduje, I. (2010). Comunas centrales crecen 22,8\% más que lo proyectado por el INE para 2010. Diario La Tercera, jueves 11 de noviembre.

Rodríguez, J. (2007). Paradojas y contrapuntos de dinámica demográfica metropolitana: algunas respuestas basadas en la explotación intensiva de microdatos censales. En C. De Mattos \& R. Hidalgo (Eds.). Santiago de Chile: Movilidad espacialy reconfiguración metropolitana. Santiago: Colección EURE Libros/ Serie GEOlibros Nº8.

Rojas, E. (2004). Volver al centro. La recuperación de áreas urbanas centrales. Nueva York: Banco Interamericano de Desarrollo. Departamento de Desarrollo Sostenible.

Rubio, D. (2009). Transformaciones en el Barrio Bellas Artes-Lastarria: ¿un proceso de gentrificación? Tesis Magíster en Desarrollo Urbano. Pontificia Universidad Católica de Chile, Santiago de Chile.

Saavedra, M.; Carrasco, G. \& Contreras, C. (2009). La revitalización urbana de Santiago. Encadenamiento entre crecimiento urbano y propuesta en valor del patrimonio. Ponencia presentada en Seminario Lima-Santiago, Santiago, Chile.

Smith, N. (1982). Gentrification and uneven development. Economic Geography, Vol. 58, No. 2, pp. $139-155$.

Smith, N. \& Lefaivre, M. (1984). A Class Analysis of Gentrification. En London \& Palen (Eds). Gentrification, Displacement and Neighborhood. Albany: University of New York Press.

Soja, E. (2008). Posmetrópolis. Estudios críticos sobre las ciudades y regiones. Madrid: Ediciones Traficantes de Sueños.

Ureta, A.; Musalem, L.; Domeyki, J.; Hofer, M. \& Sostén, N. (1987): Imperativo de la Recuperación urbana: Algunos costos de la expansión. Santiago de Chile: Documento de Trabajo, Corporación para el Desarrollo de Santiago.

Valenzuela, M. (2000). Programa de Repoblamiento: Comuna de Santiago de Chile 1990-1998. Un programa de gestión local reestructurado en nuevas formas de asociación entre el sector público y privado. Santiago: Municipalidad de Santiago, Chile. Texto no publicado. 